METALLURGY AND FOUNDRY ENGINEERING - Vol. 37, 2011, No. 2

Adam Cwudziński**, Jan Jowsa*

\title{
NUMERICAL MODELLING \\ OF NON-METALLIC INCLUSIONS SIZE DISTRIBUTION DURING LIQUID STEEL FLOW THROUGH A CONTINUOUS CASTING SLAB TUNDISH
}

\section{INTRODUCTION}

Mathematical modelling is one of the techniques that makes it possible to study and observe the course of steelmaking processes with a view to the optimization of conditions for the manufacture of good quality products [1-4]. The formation of non-metallic inclusions (NMI) in liquid steel is an undesirable phenomenon, as NMIs are the source of defects that may disqualify the steel products. The size, shape and quantity of NMIs are regulated by relevant standards. The main stimulator of the NMI formation process is the amount of the addition of elements exhibiting strong affinity to oxygen and sulphur and the amount of free oxygen or sulphur in liquid steel during refining and casting. As a consequence of chemical reactions, oxides and sulphides, or more complex compounds form. This results in a reduction of the contents of free oxygen and sulphur and an increase in the amount of a highly dispersed non-metallic phase. Associated with this phenomenon is the problem of effectiveness of removing the steel deoxidation or desulphurization reaction by-products from the liquid metal. In a situation where there is no stimulator of the NMI flotation process and MNI assimilation by the slag phase is poor, the NMIs become a source of defects in the finished product. The currently used secondary metallurgy processes remove considerable amounts of NMIs from liquid steel. The MNI removal process must also cover the subsequent steel production stages including the flow of steel through the tundish and moulds of the Continuous Steel Casting (CSC) plant. In the last two decades of the turn of the $20^{\text {th }}$ and $21^{\text {st }}$ centuries, many important scientific works originated, dealing with the processes associated with the occurrence of NMIs both in liquid and in solidified steel.

* Prof., Ph.D., D.Sc., ** Ph.D., D.Sc.: Czestochowa University of Technology, Faculty of Materials Processing Technology and Applied Physics, Czestochowa, Poland; e-mail: cwudzinski@mim.pcz.czest.pl 
Among those works, there are also studies on the role of NMIs in the tundish [5-10]. As the liquid metal resides in the tundish for a specific time, the question arises of whether it is the time sufficient for the NMIs to increase their size and flow out to the slag. Given that secondary metallurgy does not assure the $100 \%$ purity of metal being cast, the control of the state of NMIs in liquid steel at the tundish stage seems to be entirely justified. The present paper reports the results of studies on the behaviour of NMIs in liquid steel during casting of concast slabs. Using a mathematical model and appropriate numerical methods, an attempt was made to describe the process of non-metallic inclusion size variation in liquid steel in the tundish of the CSC plant.

\section{CHARACTERIZATION OF THE TEST FACILITY}

The facility covered by the evaluation of NMI behaviour is a wedge-type tundish designed for the casting of concast slab, as described in detail in the paper [11]. The liquid steel from the main ladle flows into the tundish through the ladle shroud. The flow rate of steel flowing from the tundish to the mould is controlled by the stopper rod system. The tundish is equipped with a low dam $(h=120 \mathrm{~mm})$, which incorporates two overfall windows. The liquid depth in the tundish in the feed zone is $0.7 \mathrm{~m}$, while in the stopper rod system area it being $0.92 \mathrm{~m}$. The tundish holds $25 \mathrm{Mg}$ of liquid steel. Figure 1 shows a schematic of a tundish with virtual measurement points indicated. The first measurement points is located in the axis of the feeding stream, $5 \mathrm{~mm}$ above the tundish bottom. The second measurement point is situated $215 \mathrm{~mm}$ above the dam. The third measurement point has been positioned at the tundish outlet level. All of the measurement points lie in the plane passing through the tundish inlet and outlet axes. These are the points where the NMI distribution variation process is fully monitored.

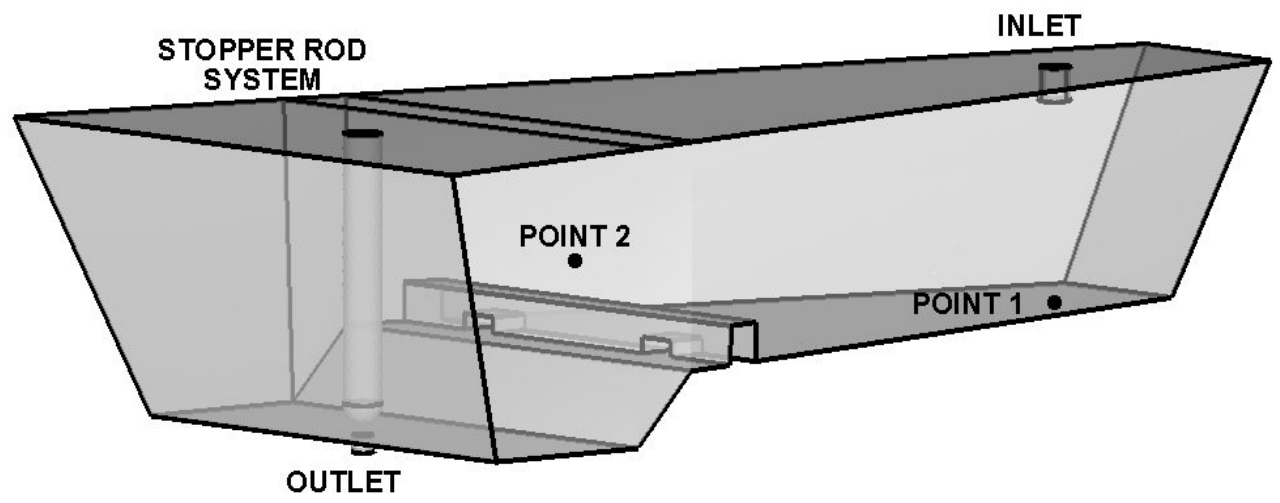

Fig. 1. View of tundish model with measurement points 


\section{MODEL DESCRIPTION}

In the first step of numerical computation, a single-phase model of turbulent motion using the $k-\varepsilon$ model was employed for the preliminary determination of the characteristics of steel motion in the tundish [12]. For the simulation of the simultaneous flow of liquid steel and non-metallic inclusions, the two-phase "mixture" model was employed, featuring the "slip velocities" option allowing the motion of both considered phases at their respective velocities. The "mixture" model is described by the equations of continuity, momentum and energy:

$$
\begin{aligned}
& \frac{\partial}{\partial t}\left(\rho_{m}\right)+\nabla \cdot\left(\rho_{m} \vec{v}_{m}\right)=0 \\
& \vec{v}_{m}=\frac{\sum_{k-1}^{n} \alpha_{k} \rho_{k} \vec{v}_{k}}{\rho_{m}} \\
& \rho_{m}=\sum_{k=1}^{n} \alpha_{k} \rho_{k} \\
& \frac{\partial}{\partial t}\left(\rho_{m} \vec{v}_{m}\right)+\nabla \cdot\left(\rho_{m} \vec{v}_{m} \vec{v}_{m}\right)=-\nabla p+\nabla \cdot\left[\mu_{m}\left(\nabla \vec{v}_{m}+\nabla \overrightarrow{v_{m}}\right)\right]+ \\
& +\rho_{m} \vec{g}+\vec{F}+\nabla \cdot\left(\sum_{k=1}^{n} \alpha_{k} \rho_{k} \vec{v}_{d r, k} \vec{v}_{d r, k}\right) \\
& \frac{\partial}{\partial t} \sum_{k=1}^{n}\left(\alpha_{k} \rho_{k} E_{k}\right)+\nabla \cdot \sum_{k=1}^{n}\left(\alpha_{k} \vec{v}_{k}\left(\rho_{k} h_{k}+p\right)\right)=\nabla \cdot\left(k_{e f f} \nabla T\right)+S_{E} \\
& \vec{\mu}_{m} r, k=\vec{v}_{k}-\vec{v}_{m} \\
& \sum_{k=1}^{n} \alpha_{k} \mu_{k}
\end{aligned}
$$

where:

$$
\begin{aligned}
t & - \text { time [s], } \\
\rho_{m} & - \text { mixture density }\left[\mathrm{kg} / \mathrm{m}^{3}\right], \\
\vec{v}_{m} & - \text { mass averaged velocity }[\mathrm{m} / \mathrm{s}] \\
\alpha_{k} & - \text { volume fraction of phase } \mathrm{k}[-],
\end{aligned}
$$




$$
\begin{aligned}
\rho_{k} & - \text { density of phase } \mathrm{k}\left[\mathrm{kg} / \mathrm{m}^{3}\right], \\
\vec{v}_{k} & - \text { velocity of phase } \mathrm{k}[\mathrm{m} / \mathrm{s}], \\
\rho_{m} & - \text { mixture density }\left[\mathrm{kg} / \mathrm{m}^{3}\right], \\
p & - \text { pressure }[\mathrm{Pa}], \\
\mu_{m} & - \text { viscosity of mixture }[\mathrm{Pa} \cdot \mathrm{s}], \\
n & - \text { number of phases, } \\
g & - \text { gravitational acceleration }\left[\mathrm{m} / \mathrm{s}^{2}\right], \\
\vec{F} & - \text { body force }[\mathrm{N}], \\
\vec{v}_{d r, k} & - \text { drift velocity of phase } \mathrm{k}[\mathrm{m} / \mathrm{s}], \\
\mu_{k} & - \text { viscosity of phase } \mathrm{k}[\mathrm{Pa} \cdot \mathrm{s}], \\
T & - \text { temperature }[\mathrm{K}], \\
S_{E} & - \text { volumetric heat sources, } \\
k_{e f f} & - \text { effective thermal conductivity }[\mathrm{W} / \mathrm{m} \cdot \mathrm{K}], \\
h_{k} & - \text { enthalpy for phase } \mathrm{k}[\mathrm{J} / \mathrm{kg}] .
\end{aligned}
$$

The relative velocity and drift velocity are presented by the following expressions:

$$
\begin{aligned}
& \vec{v}_{p q}=\vec{v}_{p}-\vec{v}_{q} \\
& c_{k}=\frac{\alpha_{k} \rho_{k}}{\rho_{m}} \\
& \vec{v}_{d r, p}=\vec{v}_{p q}-\sum_{k=1}^{n} c_{k} \vec{v}_{q k}
\end{aligned}
$$

where:

$$
\begin{aligned}
\vec{v}_{p q} & - \text { slip velocity }[\mathrm{m} / \mathrm{s}] \\
\vec{v}_{p} & - \text { velocity of secondary phase }[\mathrm{m} / \mathrm{s}], \\
\vec{v}_{q} & - \text { velocity of primary phase }[\mathrm{m} / \mathrm{s}] \\
\mathrm{c}_{k} & - \text { mass fraction for any phase } \mathrm{k}[-] \\
\alpha_{k} & - \text { volume fraction of phase } \mathrm{k}[-] \\
\rho_{k} & - \text { density of phase } \mathrm{k}\left[\mathrm{kg} / \mathrm{m}^{3}\right] \\
\rho_{m} & - \text { mixture density }\left[\mathrm{kg} / \mathrm{m}^{3}\right] \\
\vec{v}_{d r, p} & - \text { drift velocity }[\mathrm{m} / \mathrm{s}], \\
\vec{v}_{q k} & - \text { velocity of phase } \mathrm{k}[\mathrm{m} / \mathrm{s}]
\end{aligned}
$$


The behaviour of non-metallic inclusions, that is the variation in the distribution of their size as a result of mutual collisions and the diffusion growth, was described using a population balance model. In the studies of the NMI size distribution, a discrete method was employed to simulate the increase of six NMI classes in the size range from 1 to $10 \mu \mathrm{m}$. The population balance model is described by the following equations:

$$
\begin{aligned}
& \frac{\partial}{\partial t}\left(\rho_{N M I} \alpha_{i}\right)+\nabla \cdot\left(\rho_{N M I} u_{i} \alpha_{i}\right)+\frac{\partial}{\partial V}\left(\frac{G_{v} \rho_{N M I} \alpha_{i}}{V}\right)= \\
& =\rho_{N M I} V_{i}\left(B_{a g, i}-D_{a g, i}\right)+0^{i} \rho_{N M I} V_{0} \dot{n}_{0} \\
& \alpha_{i}=N_{i} V_{i}, \quad i=0,1, \ldots, N-1 \\
& N_{i}(t)=\int_{V_{i}}^{V_{i+1}} n(V, t) d V \\
& f_{i}=\frac{\alpha_{i}}{\alpha} \\
& \frac{\partial}{\partial V}\left(\frac{G_{\nu} \rho_{N M I} \alpha_{i}}{V}\right)=\rho_{N M I} V_{i}\left[\left(\frac{G_{v, i-1} N_{i-1}}{V_{i}-V_{i-1}}\right)-\left(\frac{G_{v, i} N_{i}}{V_{i+1}-V_{i}}\right)\right] \\
& B_{a g, i}=\sum_{k=1}^{N} \sum_{j=1}^{N} a_{k j} N_{k} N_{j} x_{k j} \xi_{k j} \\
& D_{a g, i}=\sum_{j=1}^{N} a_{i j} N_{i} N_{j} \\
& a_{i j}=a\left(V_{i}, V_{j}\right) \\
& \xi_{k j}= \begin{cases}1 & \text { for } \quad V_{i}<V_{a g}<V_{i+1}, \quad \text { where } i \leq N-1 \\
0 & \text { otherwise }\end{cases} \\
& V_{a g}=\left[x_{k j} V_{i}+\left(1-x_{k j}\right) V_{i+1}\right] \\
& x_{k j}=\frac{V_{a g}-V_{i+1}}{V_{i}-V_{i+1}}
\end{aligned}
$$


where:

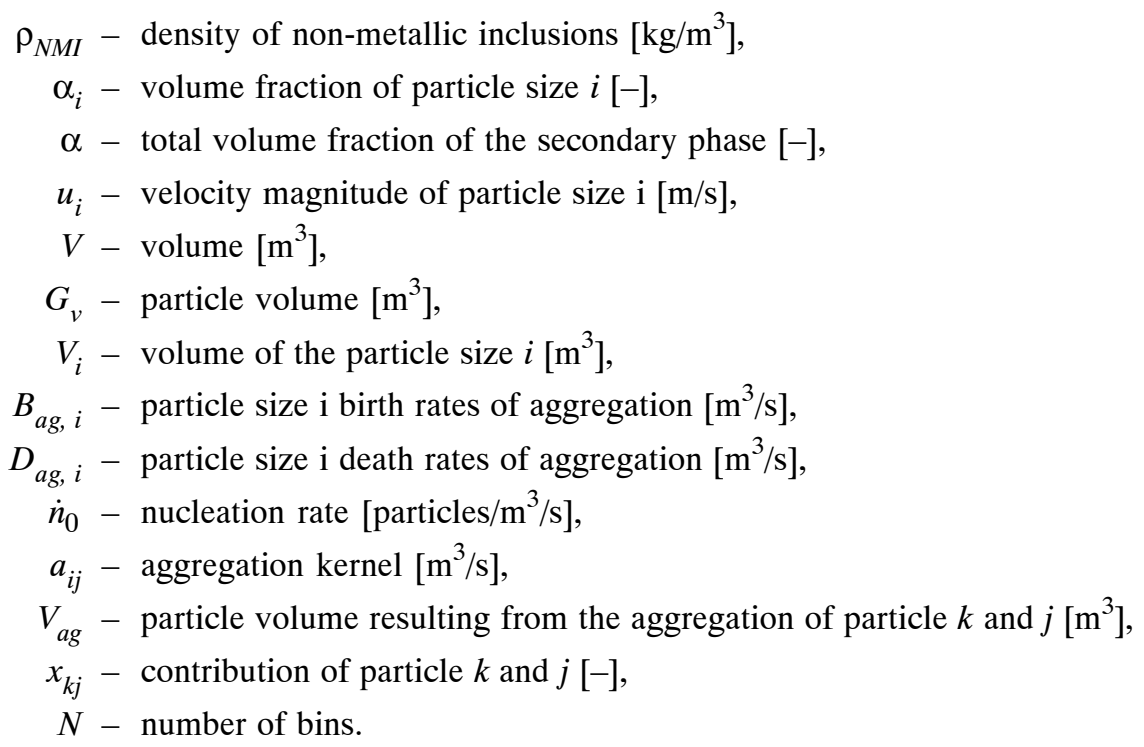

In the research six NMI classes were considered. Particular classes corresponded to a NMI group of a specific diameter, i.e. 1, 1.58, 2.51, 4, 6.3 and $10 \mu \mathrm{m}$. The share of fraction volume for each class was assumed to be at a level of 0.16 . The volumetric share of the whole NMI fraction relative to the metallic fraction was 0.0001 . The NMI growth was stimulated by three mechanisms: nucleation, diffusion and turbulent collisions. The nucleation values was assumed at a level of $1 \cdot 10^{+10}$ particles $/ \mathrm{m}^{3} / \mathrm{s}$, and the diffusion growth at a level of $1 \cdot 10^{-07} \mathrm{~m} / \mathrm{s}$. The collision kernel was represented by the turbulent collision model, in which Hamaker's constant was 2.3e-20, as described by the following equations [13]:

$$
\begin{aligned}
& a_{i j}=\mathfrak{u}_{T} \sqrt{\frac{8 \pi}{15}} \dot{\gamma} \frac{\left(V_{i}+V_{j}\right)^{3}}{8} \\
& \dot{\gamma}=\frac{\varepsilon^{0,5}}{v} \\
& \mathrm{v}_{T}=0,732\left(\frac{5}{N_{T}}\right)^{0,242} \\
& N_{T}=\frac{6 \pi \mu\left(V_{i}+V_{j}\right)^{3} \dot{\lambda}}{8 H} \\
& \dot{\lambda}=\left(\frac{4 \varepsilon}{15 \pi v}\right)^{0,5}
\end{aligned}
$$


where:

$\mathbf{t}_{T}$ - capture efficiency coefficient of turbulent collision,

$\dot{\gamma}$ - shear rate,

$\varepsilon-$ turbulent energy dissipation rate $\left[\mathrm{m}^{2} / \mathrm{s}^{3}\right]$,

$v$ - kinematic viscosity $\left[\mathrm{m}^{2} / \mathrm{s}\right]$,

$N_{T}$ - ratio between viscous force and Van der Waals force,

$\dot{\lambda}$ - deformation rate,

$H$ - Hamaker constant.

It was assumed that the non-metallic phase was represented by NMIs of the $\mathrm{Al}_{2} \mathrm{O}_{3}$ type of a density of $3960 \mathrm{~kg} / \mathrm{m}^{3}$. The remaining physicochemical quantities describing the both phases are reported in work [11]. The steel flow rate was $34.17 \mathrm{~kg} / \mathrm{s}$, which corresponded to the founding sequence of casting $1500 \times 225 \mathrm{~mm}$ concast slabs at a speed of $0.9 \mathrm{~m} / \mathrm{min}$. The temperature of steel flowing out from the tundish was $1823 \mathrm{~K}$. The initial values of the parameters $\mathrm{k}$ and $\varepsilon$ are $0.0169 \mathrm{~m}^{2} / \mathrm{s}^{2}$ and $0.062771 \mathrm{~m}^{2} / \mathrm{s}^{3}$, respectively. The numerical simulation was performed for non-isothermal and non-stationary conditions. The details concerning heat exchange between the tundish, liquid metal and the environment are given in work [14]. In the present study, the following assumptions were made: no possibility of NMI assimilation by the tundish powder forming the refining slag phase, and no capturing of NMIs on the ceramic lining of the tundish. The virtual tundish object is composed of 490000 tetrahedral elements. The system of equations forming the mathematical model of steel flow and non-metallic inclusions was solved by the method of control volumes by employing discretization of the second order upwind and Quick using the sequential solver. The algorithm SIMPLEC® (Semi-Implicit Method for Pressure-Linked Equations-Consistent) was used for the description of the coupling of the pressure and velocity fields in the model being solved. All numerical simulations were performed using the Fluent-Ansys software.

\section{COMPUTATION RESULTS}

By the computer simulations of casting of steel containing the NMI share preset at the input, the distribution of NMI size was observed, as dependent on the process duration in different tundish regions. As a result of the computations, the distribution fields of particular NMI class fractions and the curves of NMI growth during the continuous casting process were obtained. Figures 2 and 3 show NMI distribution fields after 26 minutes of the starting of the casting sequence. In contrast to Figure 3, Figure 2 shows only a fragment of the tundish region, because in the remaining tundish region variations in NMI distribution are only slight. The period of 26 minutes corresponds to over twice the mean time of residence in the tundish and can be regarded as the steady state that will settle in the tundish during sequential casting. The mean residence time of steel in the tundish for the process under 
analysis is 12 minutes. In Figures $2 \mathrm{a}$ and $2 \mathrm{~b}$ it can be seen that the NMI fraction of a size of 1 and $1.58 \mu \mathrm{m}$ undergoes considerable reduction already in the feeding stream zone. The NMI group fractions of sizes of 2.51 and $4 \mu \mathrm{m}$ change in a similar way. The 6.3 and $10 \mu \mathrm{m}$ size NMI fractions, on the other hand, are increased relative to their initial shares (Fig. 3). In the stopper rod zone, a significant share of $10 \mu \mathrm{m}$-size NMIs is observed, which reaches a level as high as $75 \%$ of the whole population of NMIs flowing with steel into the mould. The accumulation of highest-size NMIs in the vicinity of the tundish outflow can be explained by the assumed lack of possibility of NMI assimilation by the slag covering the liquid steel in the tundish.

a)

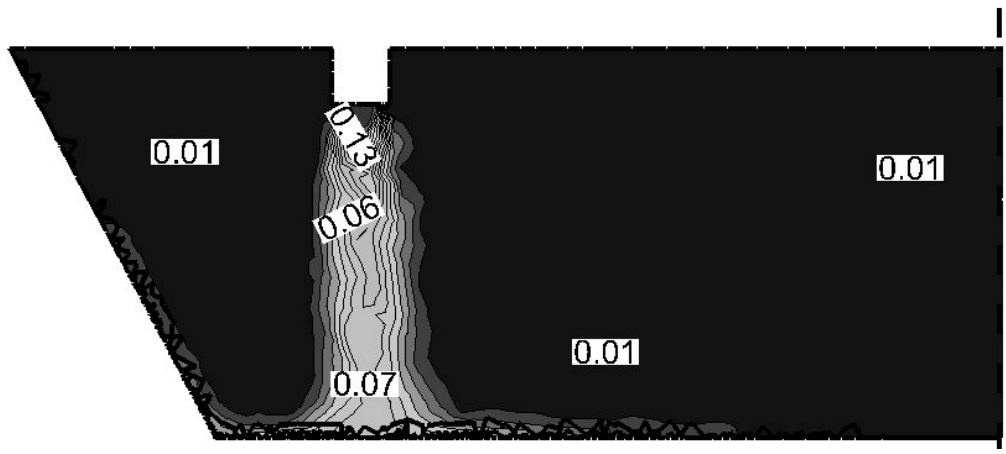

b)

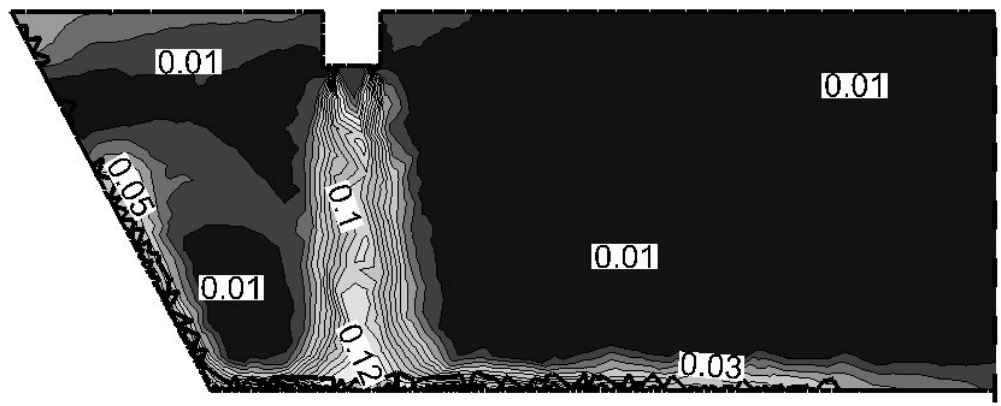

c)

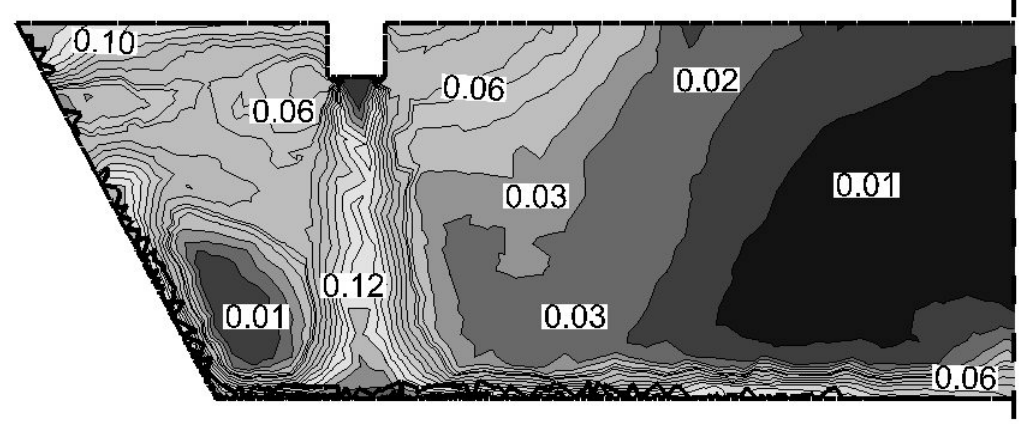

Fig. 2. Behavoiur of non-metallic inclusions in the liquid steel after 1600 second from start of casting sequence: a) NMI diameter $1 \mu \mathrm{m}$; b) NMI diameter $1.58 \mu \mathrm{m}$; c) NMI diameter $2.51 \mu \mathrm{m}$ 
a)
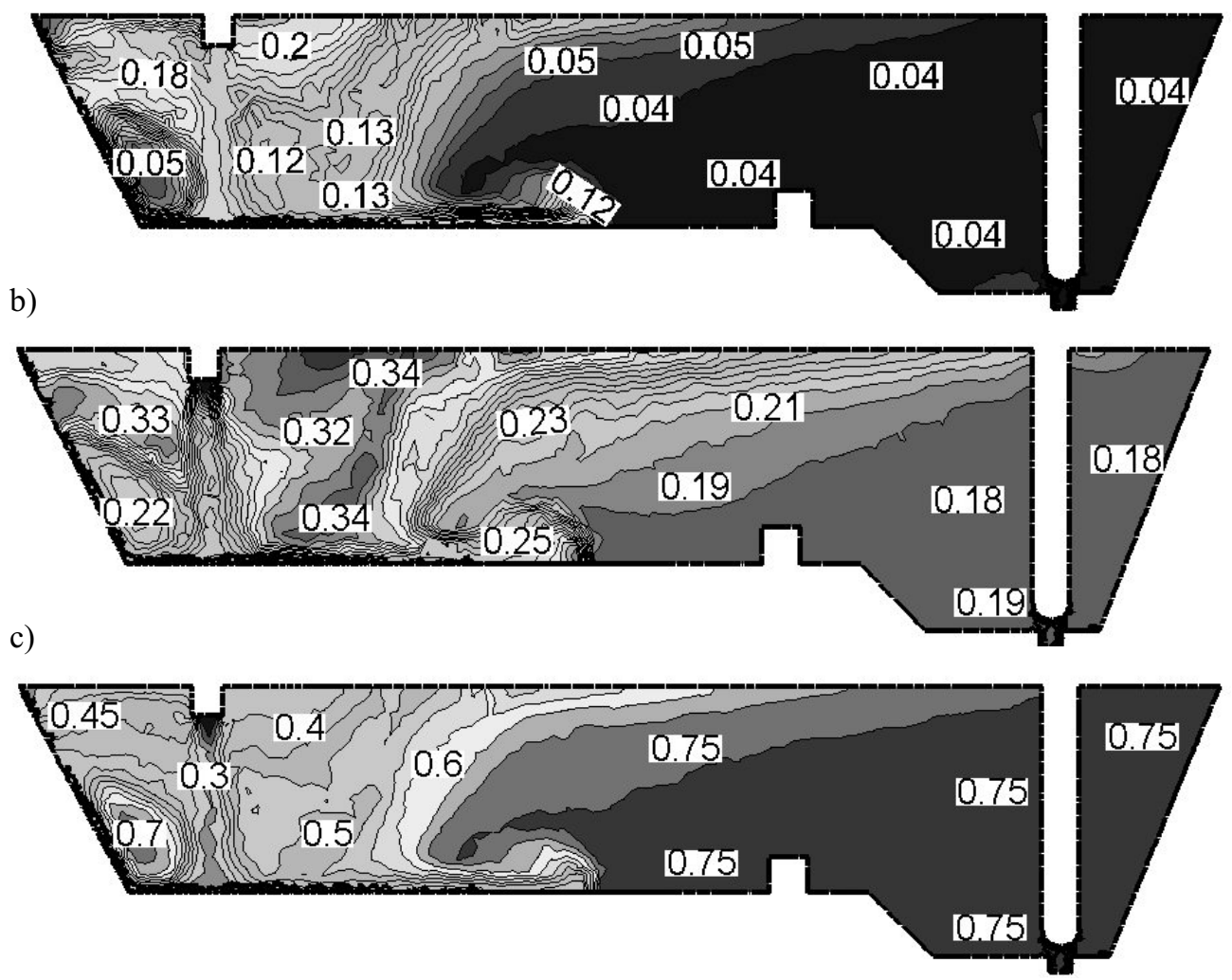

Fig. 3. Behavoiur of non-metallic inclusions in the liquid steel after 1600 second from start of casting sequence: a) NMI diameter $4 \mu \mathrm{m}$; b) NMI diameter $6.3 \mu \mathrm{m}$; c) NMI diameter $10 \mu \mathrm{m}$

To better understand the phenomenon of differentiation of NMI distribution in liquid steel in the tundish, curves plotting the fraction variation process as a function of time, as counted from the sequence start, are presented in Figures $4 \mathrm{a}-\mathrm{f}$. The individual figures show curves for the NMI fraction of a diameter from $1 \mu \mathrm{m}$ to $10 \mu \mathrm{m}$ for different monitoring points. The monitoring points are positioned in locations characteristic of the tundish. The first point is situated in the region of the greatest flow turbulence in the entire plant, so this is where the best conditions for the collision growth of NMIs exist. The second point located in the central part of the plant reflects the average hydrodynamic conditions for liquid steel motion; whereas the third point, situated at the tundish outlet, will characterize the NMI state in concast slabs being cast. By analyzing Figures $4 \mathrm{a}-\mathrm{e}$, it can be possible to easily determine from them the moving front of the liquid with NMIs within the plant. Hence it can be seen how important changes occur in the distribution of particular NMI fractions. It has been found that after the period of 1200 seconds the stabilization of NMI size differentiation takes place 
a)

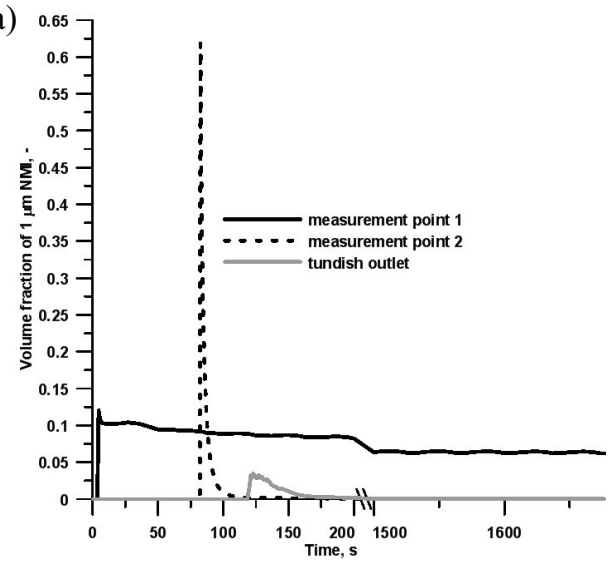

c)

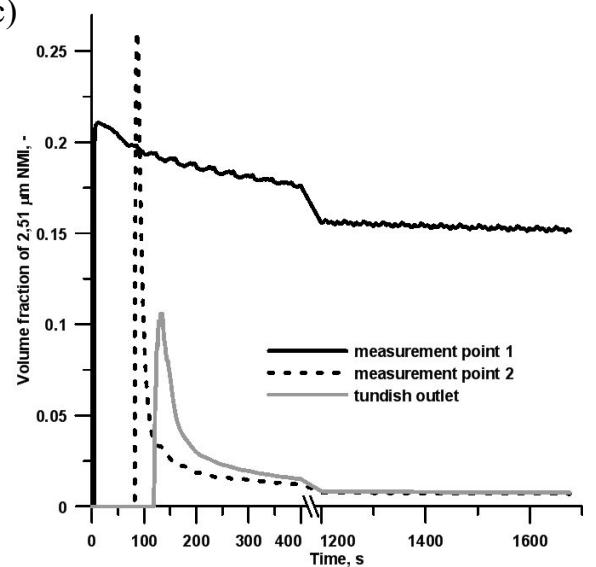

e)

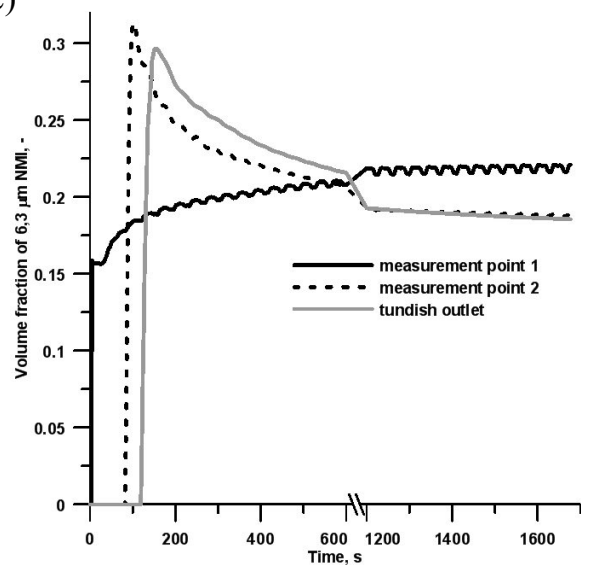

b)

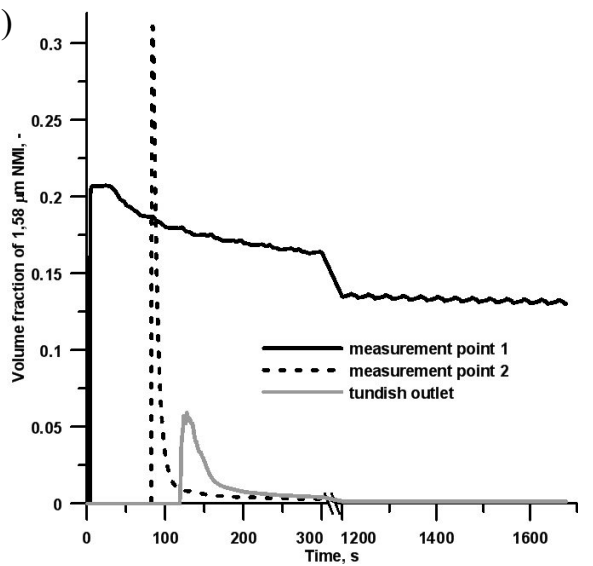

d)

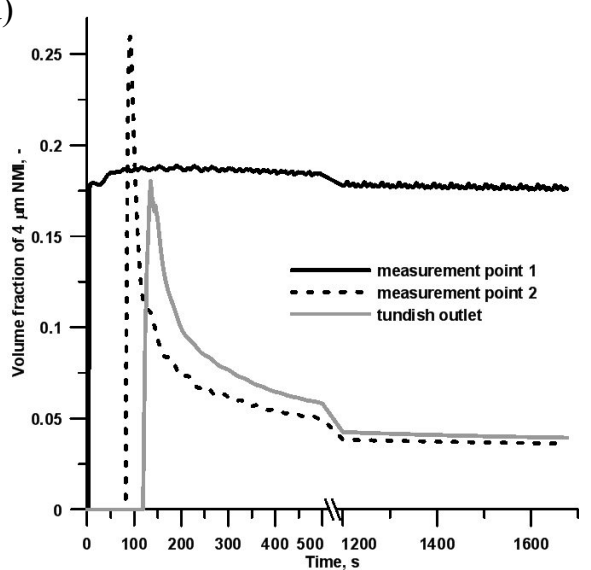

f)

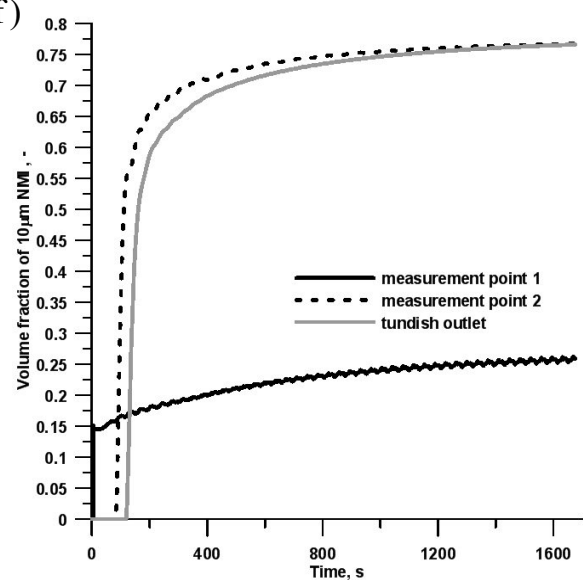

Fig. 4. Behaviour of non-metallic inclusions in the liquid steel during continuous casting slabs: a) NMI diameter $1 \mu \mathrm{m}$; b) NMI diameter $1.58 \mu \mathrm{m}$; c) NMI diameter $2.51 \mu \mathrm{m}$; d) NMI diameter $4 \mu \mathrm{m}$; e) NMI diameter $6.3 \mu \mathrm{m}$; f) NMI diameter $10 \mu \mathrm{m}$ 
The continued steel casting process has no longer a significant effect on the final distribution of non-metallic inclusions. The processes of collision (turbulent) and diffusion growth proceeding in the tundish cause substantial changes in NMI distribution compared to the initial state. Namely, a complete reduction of $1 \mu \mathrm{m}$-size NMIs and 99, 95 and $76 \%$ reductions of NMIs of sizes of 1.56, 2.51 and $4 \mu \mathrm{m}$ take place. As a consequence, an increase in the share of NMIs of diameters of 6.3 and $10 \mu \mathrm{m}$ occurs by 11 and $359 \%$, respectively.

\section{SUMMARY}

From the numerical computations carried out, the pattern of non-metallic inclusion behaviour in the liquid metal volume in the tundish during continuous casting of steel concast slabs was obtained. The presented results indicate the complexity of the process of differentiation of NMI fraction distribution in liquid steel. This is evidenced by a considerable reduction in the quantity of small NMIs, and an increase in the share of larger-size NMIs, as observed in specific locations of the tundish. As the casting time goes by, the NMI distribution differentiation process appears to stabilize. The greatest increase in the volume magnitude has occurred for the $10 \mu \mathrm{m}$-size NMI fraction; it has increased from 0.16 to 0.75 , which means a relative increase a high as $359 \%$. Hence there is a real need for modifying the internal space of the tundish and spreading the assimilation-insulation powder onto the free liquid steel table in order to create conditions for a better elimination of large NMIs formed from the liquid metal. The next research stage will include attempts to change the description of the mechanism of NMI growth in the tundish with the aim of determining the extent of possible modification to the NMI size distribution.

\section{Acknowledgements}

This scientific work has been financed from the resources allocated for Science in the years 2009-2011 as Research Project No. N508390437. This publication has been made with the financial support by the Foundation for Polish Science

\section{REFERENCES}

[1] Quick M., Morris J.: AISTech 2006 Proceedings, Vol. II (2006) 501-510

[2] Timmel K., Eckert S. Gerbeth G., Stefani F., Wondrak T.: ISIJ Int., Vol. 50 (2010) 1134-1141

[3] Cho M.J., Kim S.J.: ISIJ Int., Vol. 50 (2010) 1175-1179

[4] Espino-Zarate A., Morales R.D., Najera-Bastida A., Macias-Hernandez M.J., Sandoval-Ramos A.: Metal. Mater. Trans. B., Vol. 41B (2010) 962-975

[5] Bessho N., Yamasaki H., Fuji T., Nozaki T., Hiwasa S.: ISIJ Int., Vol. 32 (1992) 157-163

[6] Zhang L.: $5^{\text {th }}$ Int. Conf. on CFD in the Process Industries CSIRO (2006) 1-11 
[7] Wang Y., Wen G., Tang P., Zhu M., Chen Y., Song W.: J. Univ. of Sci. Technol. Beijing, Vol. 14 (2007) 22-26

[8] Zheng S.-g., Zhu M.-y.: Steel Res. Int., Vol. 79 (2008) 685-690

[9] Kislitsa V.V., Isaev O.B., Matrosov Y.I., Belousov V.V., Gonchar B.S., Diyuk E.F.: Steel in Translation, Vol. 39 (2009) 677-680

[10] Deryabin A.A., Mogil'nyi V.V.: Steel in Translation, Vol. 40 (2010) 464-471

[11] Cwudziński A.: Ironmaking Steelmaking, Vol. 37 (2010) 169-180

[12] Cwudziński A., Jowsa J.: Archiv. Metall. Mater., Vol. 53 (2008) 749-761

[13] Population Balance Module Manual, Ansys-Fluent 12.0 (2009)

[14] Cwudziński A., Jowsa J.: Metall. Found. Eng., Vol. 33 (2007) 97-103

Received

January 2011 